\title{
A Simple Fatigue Life Prediction Algorithm Using the Modified NASGRO Equation
}

\author{
Wei Zhang, Qiang Wang, Xiaoyang Li, and Jingjing He \\ Science and Technology on Reliability and Environmental Engineering Laboratory, \\ School of Reliability and Systems Engineering, Beihang University, Beijing 100191, China
}

Correspondence should be addressed to Wei Zhang; zhangwei.dse@buaa.edu.cn

Received 10 April 2016; Accepted 2 June 2016

Academic Editor: Giovanni Garcea

Copyright (C) 2016 Wei Zhang et al. This is an open access article distributed under the Creative Commons Attribution License, which permits unrestricted use, distribution, and reproduction in any medium, provided the original work is properly cited.

A simple fatigue life prediction algorithm using the modified NASGRO equation is proposed in this paper. The NASGRO equation is modified by introducing the concept of intrinsic effective threshold stress intensity factor (SIF) range $\left(\Delta K_{\text {eff }}\right)_{\text {th }}$. One advantage of the proposed method is that the complex growth behavior analysis of small cracks can be avoided, and then the fatigue life can be calculated by directly integrating the crack growth model from the initial defect size to the critical crack size. The fatigue limit and the intrinsic effective threshold SIF range $\left(\Delta K_{\text {eff }}\right)_{\text {th }}$ are used to calculate the initial defect size or initial flaw size. The value of $\left(\Delta K_{\mathrm{eff}}\right)_{\mathrm{th}}$ is determined by extrapolating the crack propagation rate curves. Instead of using the fatigue limit determined by the fatigue strength at the specific fatigue life, the fatigue limit is selected based on the horizontal tendency of the $S$ - $N$ curve. The calculated fatigue lives are compared to the experimental data of two different alloys. The predicted $S$ - $N$ curves agree with the test data well. Besides, the prediction results are compared with that calculated using the FASTRAN code. Results indicate that the proposed life prediction algorithm is simple and efficient.

\section{Introduction}

Despite more than one hundred years of research, the fatigue life prediction is still a challenging problem. The traditional cumulative fatigue damage (CFD) theories are often used for predicting the fatigue life of structural materials. Different CFD formulas are proposed to predict the $S-N$ curve, such as the famous Basquin form [1] in the stress-based method and the Coffin-Manson relationship [2,3] in the strain-based method. It should be noted that many factors can affect the fatigue life, such as the material geometry $[4,5]$, the stress state [6-9], and the effect of environment [10-12]. But these factors are not taken into account in the CFD-based life prediction method. Besides, there are no clear definitions for the fatigue failure in above methods. In a sense, the CFD-based life prediction models are more experience-based rather than physical.

With the advent and technical developments of Linear Elastic Fracture Mechanics (LEFM) theories and computer science, large efforts have been devoted to predict or to understand the crack growth behavior. The Irwin stress intensity factor (SIF) range was first used by Paris and Erdogan [13] to characterize the crack growth behavior under external cycle loading, and the crack propagation rate is characterized using the SIF range concept. Since then, several crack propagation models were proposed, such as the Priddle equation [14] and the Forman model [15], and the crack growth behavior was divided into three stage: the near threshold region, the Paris region, and the unstable crack propagation region. The discovery of crack closure by Elber [16] was another major step in the crack growth analysis. The crack closure is a physical phenomenon that the crack is already closed before the external tensile loading is completely unloaded, and also the crack will still remain closed until the external tensile loading reaches a certain level. It is reported that many mechanism models can explain the crack closure phenomenon, such as the plasticity-induced crack closure [16], the oxide-induced crack closure [17], and the roughness-induced crack closure [18]. Among them, Newman's finite element model is the best and deserves future developments [19]. Newman's strip yield model [20,21] was based on the Dugdale model [22] and was then further developed and implemented into the NASGRO 
software $[23,24]$ and the FASTRAN code [25]. Even when these advanced crack growth models which are based on the crack closure are proposed, it is still a tough task today to calculate the fatigue life by directly integrating the crack propagation model from the initial defect size to the critical crack length.

Newman Jr. et al. [26-28] calculated the fatigue lives of various materials and specimen configurations using the FASTRAN code and small-crack theory. The life prediction model imbedded in the FASTRAN code is Newman's crack closure model. It is known that the growth behavior of small cracks is far different from that of large cracks [29, 30], and the small-crack growth mechanism has not been fully understood yet. Besides, the traditional SIF range $\Delta K$ solution may not be applicable to a small crack if the crack initiates from a subsurface inclusion [31]. The other problem is that the value of $\left(\Delta K_{\text {eff }}\right)_{\text {th }}$ and initial defect size which are the key parameters in the LEMF-based life prediction method are selected via trial and error. This paper is aimed at simplifying the life prediction algorithm by using the modified NASGRO equation and the equivalent initial flaw size (EIFS) concept [32]. The fatigue lives can be calculated by directly integrating the crack growth model from the initial defect size to the critical crack size. The complex growth mechanism of a small crack can be ignored in the proposed method. In addition, the value of $\left(\Delta K_{\text {eff }}\right)_{\text {th }}$ is determined by extrapolating the $d a / d N \sim \Delta K_{\text {eff }}$ relation and the EIFS concept is used to calculate the initial defect size.

\section{Fatigue Life Prediction Algorithm}

The plasticity-induced crack closure was discovered by Elber [16], and then many numerical models were proposed to simulate the crack closure phenomenon. Newman Jr. firstly developed a ligament or strip yield model $[20,21]$ based on the Dugdale model framework, and the model was further developed and implemented into the NASGRO code [23, 24] which is widely used for the crack growth analysis; the equation is expressed as

$$
\frac{d a}{d N}=C_{1}\left(\Delta K_{\mathrm{eff}}\right)^{C_{2}} \frac{\left(1-\Delta K_{\mathrm{th}} / \Delta K\right)^{p}}{\left(1-K_{\max } / K_{c}\right)^{q}}
$$

where $C_{1}, C_{2}, p$, and $q$ are materials constants. $\Delta K_{\text {th }}$ is the threshold SIF range, $\Delta K$ is the SIF range, $K_{\max }$ is the maximum SIF, $K_{c}$ is the critical SIF, and $\Delta K_{\text {eff }}$ is the effective SIF range and can be expressed as a function of $\Delta K$ and $U$ :

$$
\Delta K_{\mathrm{eff}}=U \Delta K
$$

where $U$ is a function of the stress ratio $R$ and Newman's crack opening function $f$ and is expressed as

$$
U=\frac{1-f}{1-R}
$$

For constant loading, $f$ is expressed as [21]

$$
\begin{aligned}
& f \\
& = \begin{cases}\max \left(R, A_{0}+A_{1} R+A_{2} R^{2}+A_{3} R^{3}\right) & R \geq 0 \\
A_{0}+A_{1} R & -2 \leq R<0,\end{cases}
\end{aligned}
$$

where

$$
\begin{aligned}
A_{0} & \\
= & \left(0.825-0.34 \alpha+0.05 \alpha^{2}\right)\left[\cos \left(\frac{(\pi / 2) S_{\max }}{\sigma_{0}}\right)\right]^{1 / \alpha}, \\
A_{1} & =(0.415-0.071 \alpha) \frac{S_{\max }}{\sigma_{0}} \\
A_{2} & =1-A_{0}-A_{1}-A_{3} \\
A_{3} & =2 A_{0}+A_{1}-1
\end{aligned}
$$

$S_{\max } / \sigma_{0}$ and $\alpha$ are used to calculate the crack open function $f$ in NASGRO software. According to the NASGRO user manual, $S_{\max } / \sigma_{0}$ is selected as 0.3 in general $[23,24] . \alpha$ is the constraint factor which is used to consider the stress state effect. Theoretically, $\alpha$ is 1 in the plane stress condition and 3 in the plane strain condition. For the aluminum alloy, $\alpha$ were selected from 1.7 to 2 in general [26]. In this paper, $\alpha$ is assumed to be 2. $p$ controls the shape in the threshold region and should be calibrated using the experimental data in the threshold region. For the reason that the crack growth data in the threshold region are not sufficient or even not available, an initial value of $p$ is guessed. In the NASGRO database [23, 24], some typical values of $p$ can be used here. In this paper, $p$ is selected as 1 for Al2024-T3 and 1.5 for Al7075-T6. $C_{1}$ is the material constant and $C_{2}$ is the Paris exponent, and they can be calibrated using the crack propagation data in the Paris region.

The value of $\Delta K_{\mathrm{th}}$ is the key parameter for life prediction algorithm based on the LEFM and is often used in the fatigue crack growth analysis. It defines a value below which the fatigue crack will cease to grow or the growth rate is slow enough to be neglected. It is known that the crack nucleation and the small-crack growth consume most of the fatigue life [33]. Hence, the fatigue life is very sensitive to the threshold SIF range. The accuracy of the value of $\Delta K_{\text {th }}$ will have a large impact on model predictions based on the LEMF. Experiments are the main methods to obtain the values of $\Delta K_{\text {th }}$ in the current research, such as the loadreduction test method in ASTM E647 and the compression precracking method [34]. In other words, the value of $\Delta K_{\text {th }}$ highly depends on the experimental techniques which may lead to quite different measurements of $\Delta K_{\text {th }}$. In the current work, the concept of "intrinsic effective threshold stress intensity factor" $\left(\Delta K_{\text {eff }}\right)_{\text {th }}$ is introduced considering the crack closure effect and is considered to be the material property which is independent of the stress ratios or experimental technique. Similar concept is also used in Newman's fatigue life prediction model $[26,27,35]$, but the value of $\left(\Delta K_{\text {eff }}\right)_{\text {th }}$ in this paper is not determined via trial and error and is obtained 
by extrapolating the crack growth rata curve, that is, $d a / d N \sim$ $\Delta K_{\text {eff }}$ in the logarithm linear region to $10^{-10} \mathrm{~m} /$ cycle. The NASGRO equation is hence modified as

$$
\frac{d a}{d N}=C_{1}\left(\Delta K_{\mathrm{eff}}\right)^{C_{2}} \frac{\left[1-\left(\Delta K_{\mathrm{eff}}\right)_{\mathrm{th}} / \Delta K_{\mathrm{eff}}\right]^{p}}{\left(1-K_{\mathrm{max}} / K_{c}\right)^{q}} .
$$

Since only a very small part of fatigue life is consumed in the fast crack propagation stage, (6) is hence simplified as

$$
\frac{d a}{d N}=C_{1}\left[\Delta K_{\mathrm{eff}}\right]^{C_{2}}\left[1-\frac{\left(\Delta K_{\mathrm{eff}}\right)_{\mathrm{th}}}{\Delta K_{\mathrm{eff}}}\right]^{p}
$$

Fatigue life $N$ is expressed as

$$
N=\int_{a_{i}}^{a_{c}} \frac{1}{C_{1}\left[\Delta K_{\mathrm{eff}}\right]^{C_{2}}\left[1-\left(\Delta K_{\mathrm{eff}}\right)_{\mathrm{th}} / \Delta K_{\mathrm{eff}}\right]^{p}} d a,
$$

where $a_{c}$ is the critical crack size when the fatigue failure occurs. $a_{c}$ can be set as a constant in the numerical simulation, since the fatigue life consumed in the fast crack propagation stage is negligible. $a_{i}$ is the initial defect size and is often determined by solving the El Haddad equation [36]; the equation is expressed as

$$
\Delta K_{\mathrm{th}}=\Delta \sigma_{f} \sqrt{\pi c} F
$$

where $\Delta \sigma_{f}$ is the fatigue limit, $c$ represents the surface crack length, and $F$ represents the boundary correction factor. Multiply both sides of (9) by $U$, and (9) can be expressed as

$$
\left(\Delta K_{\mathrm{eff}}\right)_{\mathrm{th}}=\Delta \sigma_{f} \sqrt{\pi c} F U
$$

where $\left(\Delta K_{\mathrm{eff}}\right)_{\text {th }}=U \Delta K_{\text {th }}$ and $U=(1-f) /(1-R) .\left(\Delta K_{\mathrm{eff}}\right)_{\text {th }}$ is the intrinsic effective threshold SIF range. $a_{i}$ in this paper is determined by solving (10).

In the current study, smooth and circular-hole specimens are used to validate the proposed method, as shown in Figure 1. The surface crack for a smooth specimen is modeled as a semicircular surface crack; that is, the crack depth is equal to the surface crack length. The boundary correction factor $F$ for a surface crack is expressed as [37]

$$
F=M_{0} g_{1} f_{\varphi} f_{w} f_{x}
$$

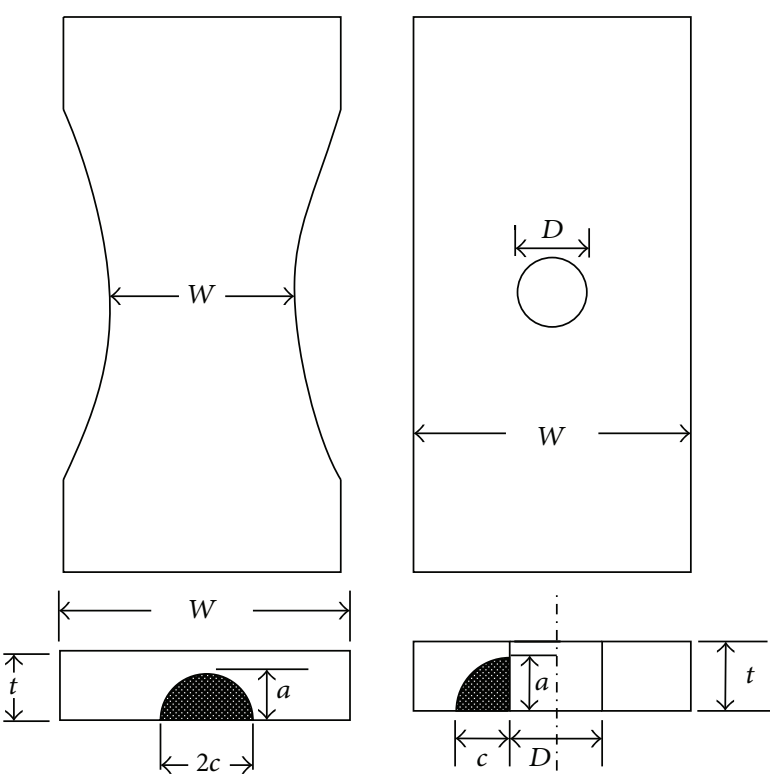

FIGURE 1: Schematic representation of a semicircular surface crack and a corner crack from a hole.

where

$$
\begin{aligned}
& M_{0}=\left(m_{1}+m_{2}\left(\frac{a}{t}\right)^{2}+m_{3}\left(\frac{a}{t}\right)^{4}\right), \\
& m_{1}=1.13-0.09\left(\frac{a}{c}\right), \\
& m_{2}=-0.54+\frac{0.89}{(0.2+(a / c))}, \\
& m_{3}=0.5-\frac{1}{(0.65+(a / c))}+14\left(1-\left(\frac{a}{c}\right)\right)^{24}, \\
& g_{1}=1+\left(0.1+0.35\left(\frac{a}{t}\right)^{2}\right)(1-\sin \varphi)^{2}, \\
& f_{\varphi}=\left(\sin \varphi+\left(\frac{a}{c}\right)^{2} \cos ^{2} \varphi\right)^{0.25}, \\
& f_{w}=\sqrt{\sec \left(\frac{\pi c}{W} \sqrt{\frac{a}{t}}\right),} \\
& f_{x}=\left(1+1.464\left(\frac{a}{c}\right) 1.65\right)^{-0.5},
\end{aligned}
$$

where $a$ is the surface crack depth, $2 c$ is the surface crack length, $W$ is the plate width, and $t$ is the plate thickness. In this paper, only crack growth in the surface crack tip is considered and its SIF range $(\varphi=0)$ is used in (10). The surface crack for a circular-hole specimen is modeled as a quarter-circular corner crack, as shown in Figure 1, and the corresponding boundary correction factor is available in the literature [38]. 
TABLE 1: Specimen geometry of Al2024-T3.

\begin{tabular}{lcccc}
\hline Specimen types & $R$ & Width $(\mathrm{mm})$ & Thickness $(\mathrm{mm})$ & Hole diameter $(\mathrm{mm})$ \\
\hline \multirow{3}{*}{ Smooth } & 0 & 25.4 & 2.3 & $/$ \\
& -1 & 25.4 & 2.3 & $/$ \\
\hline Circular-hole & 0.1 & 10.0 & 5.0 & $/$ \\
\hline
\end{tabular}

TABLE 2: Specimen geometry of Al7075-T6.

\begin{tabular}{lcccc}
\hline Specimen types & $R$ & Width $(\mathrm{mm})$ & Thickness $(\mathrm{mm})$ & Hole diameter $(\mathrm{mm})$ \\
\hline \multirow{2}{*}{ Smooth } & 0 & 25.4 & 2.3 & $/$ \\
& -1 & 50.8 & 4.8 & $/$ \\
\hline Circular-hole & $0 /-1$ & 50.8 & 2.3 & 1.6 \\
\hline
\end{tabular}

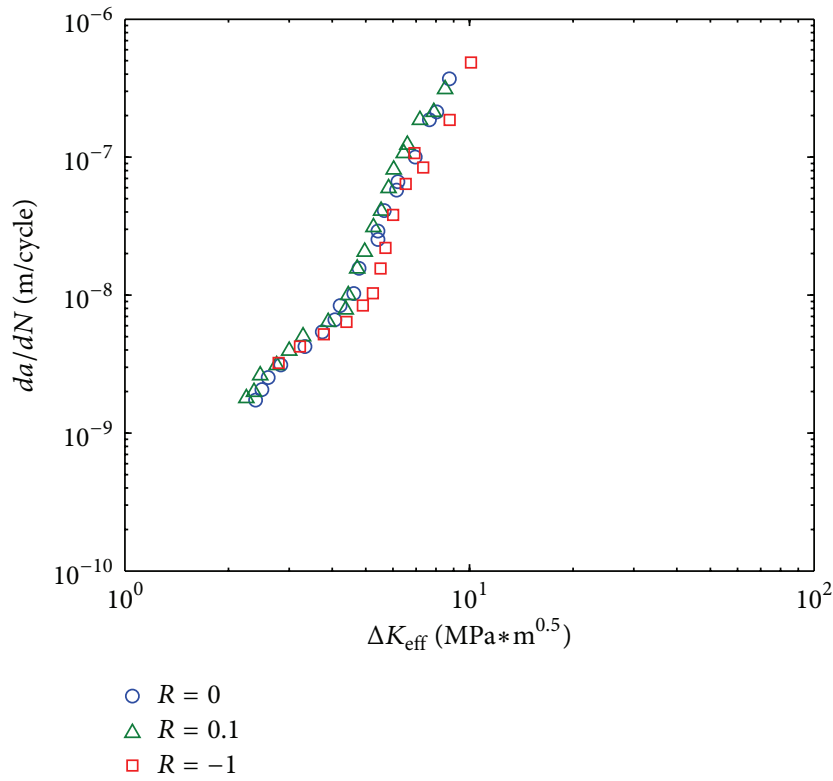

(a) Al2024-T3

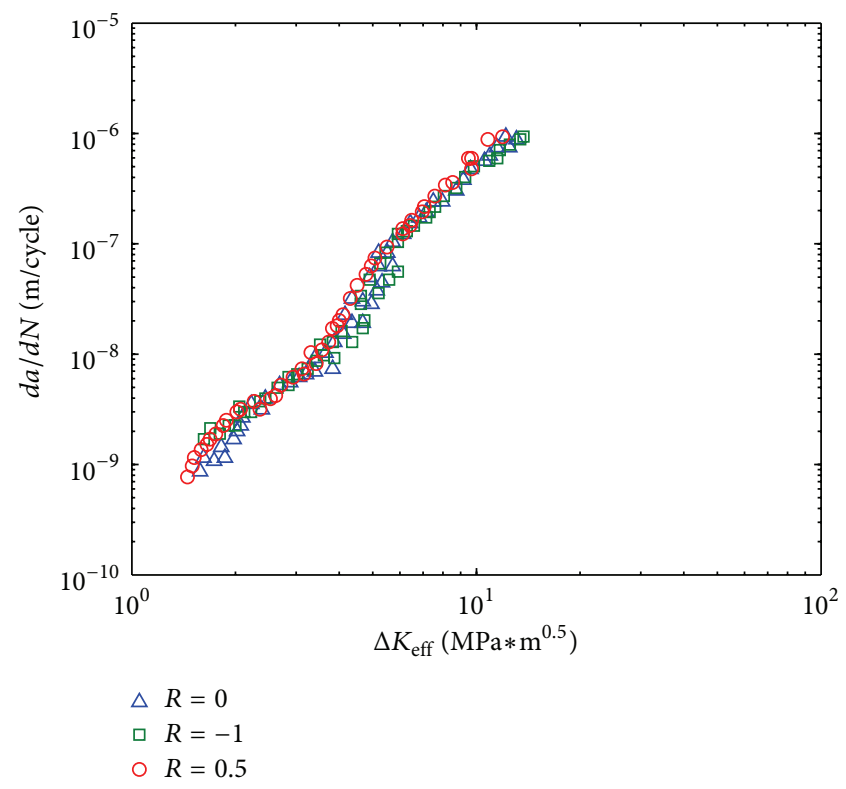

(b) Al7075-T6

Figure 2: Crack growth data of Al2024-T3 and Al7075-T6.

For low-cycle fatigue condition, the plastic zone effect cannot be neglected. The SIF range considering the plastic zone effect is expressed as

$$
\Delta K^{\prime}=\Delta \sigma_{f} \sqrt{\pi d} F^{\prime}
$$

where $d=c+\rho, F^{\prime}$ is the boundary correction factor considering the plasticity correction, and the plasticity correction factor $\rho$ is given by [32]

$$
\rho=c\left(\sec \left(\frac{\pi \sigma_{\max }(1-R)}{4 \sigma_{0}}\right)-1\right),
$$

where $\sigma_{\max }$ is the maximum stress and $\sigma_{0}$ is the flow stress and is equal to the average of the ultimate strength and yield strength.

\section{Model Validation for Smooth and Circular-Hole Specimens}

3.1. Experimental Data. The crack growth rate data of Al2024-T3 and Al7075-T6 under different stress ratios are collected from the literature [39]. They are used to calibrate parameters $C_{1}$ and $C_{2}$ in (8). Figure 2 shows the $d a / d N \sim$ $\Delta K_{\text {eff }}$ relation of Al2024-T3 and Al7075-T6. For Al2024-T3, the calibrated parameters $C_{1}=3.5535 E-11, C_{2}=4.059$, and the corresponding $\left(\Delta K_{\text {eff }}\right)_{\text {th }}$ is $1.2903 \mathrm{MPa}$. For Al7075T6, $C_{1}=1.5779 E-10, C_{2}=3.477$, and the corresponding $\left(\Delta K_{\text {eff }}\right)_{\text {th }}$ is $0.8771 \mathrm{MPa}$.

The fatigue life test data of Al2024-T3 and Al7075-T6 are collected from the open literature [26, 40, 41], and the corresponding geometric sizes are listed in Tables 1 and 2 . The fatigue properties for two different aluminum alloys used here are listed in Table 3. $\Delta \sigma_{s}$ and $\Delta \sigma_{h}$ are the fatigue limits of 
TABLE 3: Mechanical properties and fatigue properties for Al2024-T3 and Al7075-T6.

\begin{tabular}{|c|c|c|c|c|c|c|c|}
\hline Materials & $R$ & $\sigma_{y}(\mathrm{MPa})$ & $\sigma_{u}(\mathrm{MP})$ & $\Delta \sigma_{s}(\mathrm{MPa})$ & $\Delta \sigma_{h}(\mathrm{MPa})$ & $\operatorname{EIFS}_{s}(\mu \mathrm{m})$ & $\operatorname{EIFS}_{h}(\mu \mathrm{m})$ \\
\hline \multirow{3}{*}{ Al2024-T3 } & 0 & 360 & 490 & 200 & 110 & 50.68 & 24.77 \\
\hline & 0.1 & 360 & 490 & 170 & 1 & 61.04 & I \\
\hline & -1 & 360 & 490 & 285 & 110 & 73.19 & 86.57 \\
\hline \multirow{2}{*}{ Al7075-T6 } & 0 & 520 & 575 & 205 & 120 & 22.95 & 9.75 \\
\hline & -1 & 501 & 569 & 415 & 130 & 15.14 & 27.96 \\
\hline
\end{tabular}

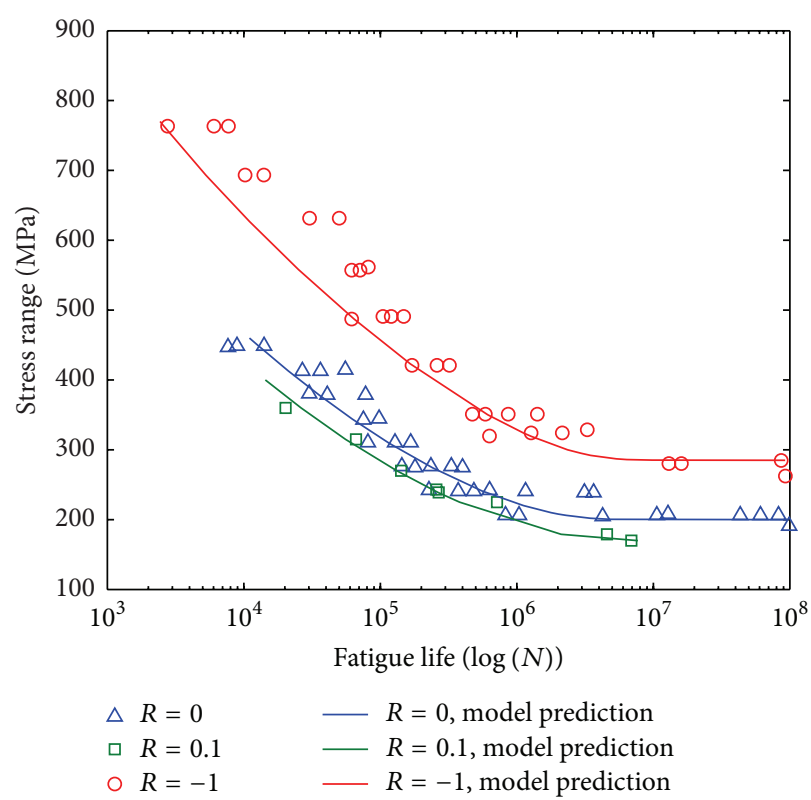

(a) Al2024-T3

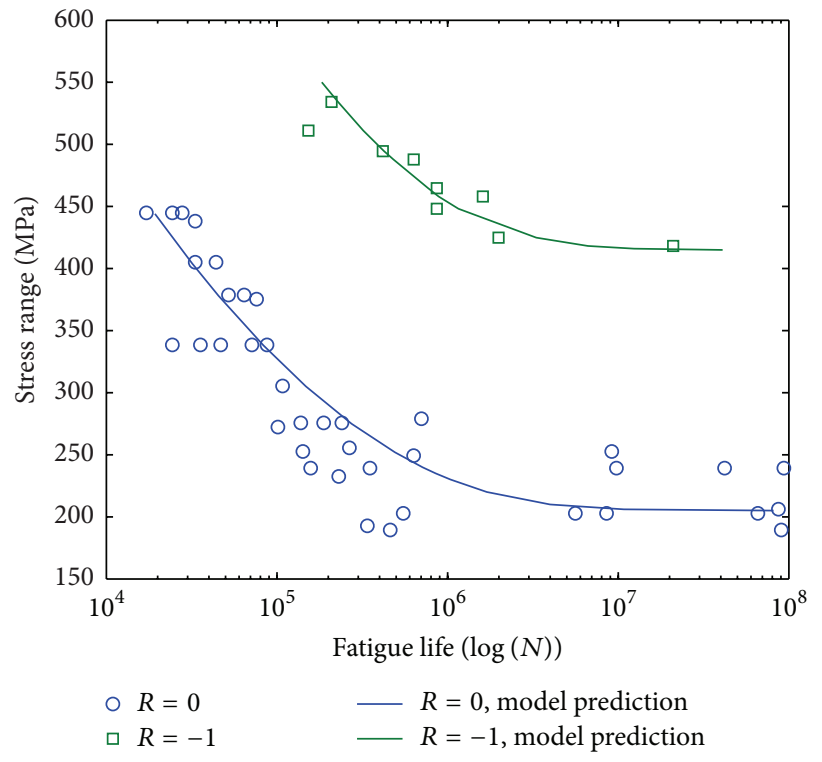

(b) Al7075-T6

FIGURE 3: Experimental data and calculated fatigue lives for smooth specimens.

smooth and circular-hole specimens, respectively. EIFS $_{s}$ and EIFS $_{h}$ calculated by using (10) are the corresponding EIFS.

3.2. Life Prediction for Smooth Specimens. The predicted $S-N$ curves using the proposed method are compared with experimental data under different stress ratios, as shown in Figure 3. The solid lines represent predicted $S-N$ curves and the solid marks are experimental data. The predicted fatigue lives are consistent with experimental data.

3.3. Life Prediction for Circular-Hole Specimens. Figure 4 shows the calculated fatigue lives and test data. The predicted fatigue lives agree well with the experimental data.

\section{Discussion and Conclusions}

Newman Jr. et al. [26] calculated the fatigue lives of two aluminum alloys using the FASTRAN code, and the life prediction model imbedded is Newman's crack closure model. In Newman's life prediction approach, the values of $\left(\Delta K_{\text {eff }}\right)_{\text {th }}$ and initial defect size, which are the key parameters in the LEMF-based life prediction method, are empirically selected via trial and error to fit the experimental data. In a sense, it is more experience-based rather than physical. In this study, the fatigue life is calculated by integrating the modified NASGRO equation from the initial defect size to the final crack size. The extrapolation method is used to determine the value of $\left(\Delta K_{\text {eff }}\right)_{t h}$, and the initial defect size is estimated using the EIFS concept. In Figure 5, the life predictions of the proposed model are compared with the experimental data and Newman et al.s results [26]. Solid lines are the numerical calculation results using the proposed algorithm, and the dashed lines are Newman's prediction results. The calculated fatigue lives are a little conservative compared with Newman's model predictions in the low-cycle fatigue region. In the middle and high cycle fatigue region, the prediction results of both methods are nearly the same. However, Newman's life prediction algorithm is very complicated and experiencebased. On the whole, the life prediction algorithm proposed in this paper is more simple and efficient.

Fatigue limit is the main parameter used to calculate the EIFS. However, studies show that the fatigue limit may not exist for metallic materials in the very high cycle fatigue (fatigue life longer than $10^{7}$ cycles in general) [42, 43]. In this paper, the fatigue limit is determined based on the test data in the region where the fatigue life is larger than $10^{6}$ cycles. If the experimental data show obvious horizontal tendency in this region and have little dispersion, the conservative data 


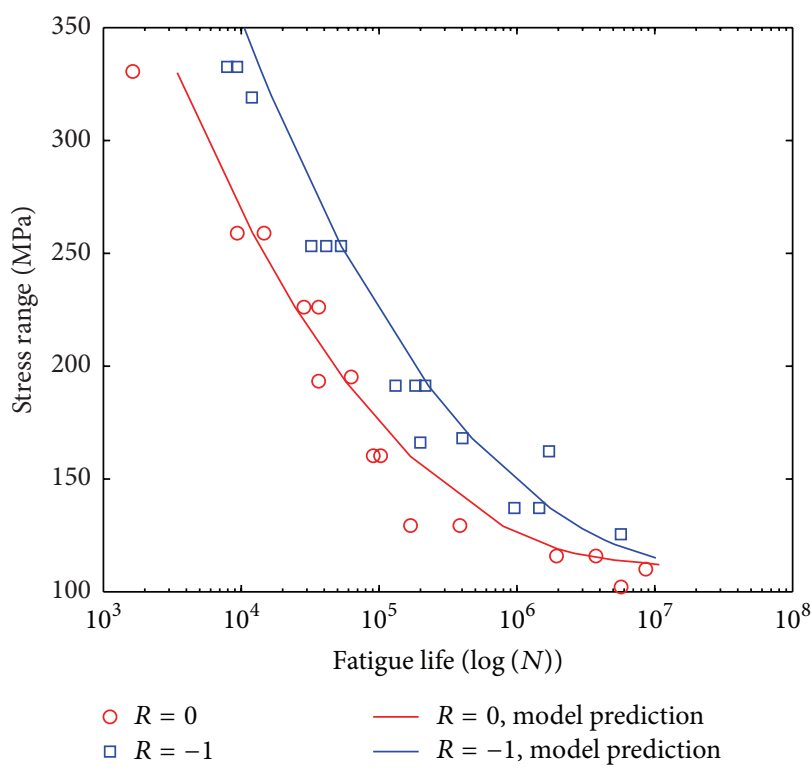

(a) $\mathrm{Al}-2024-\mathrm{T} 3$

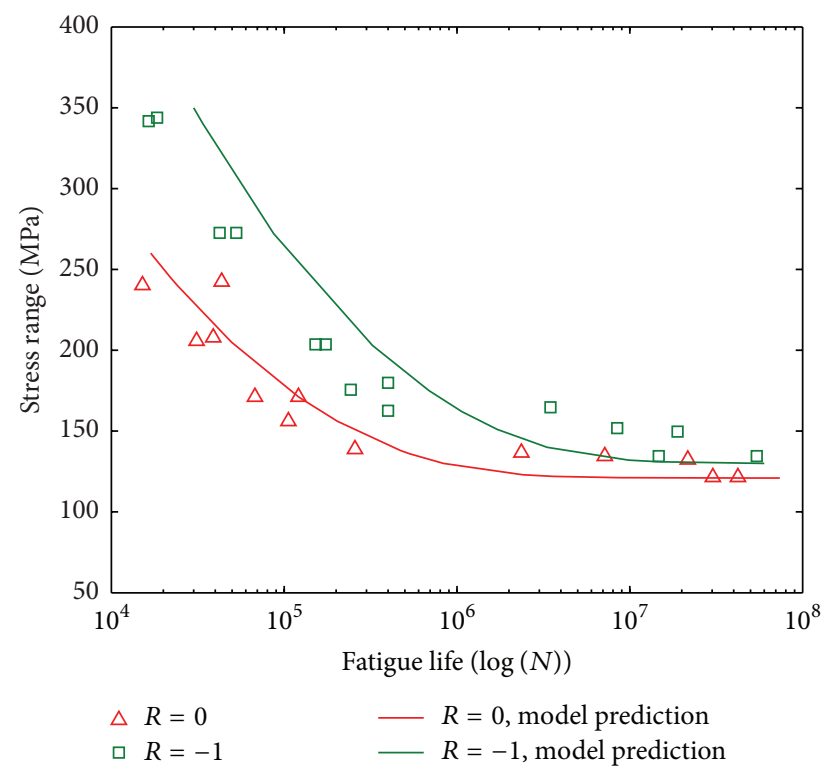

(b) Al7075-T6

FIGURE 4: Experimental data and calculated fatigue lives for circular-hole specimens.

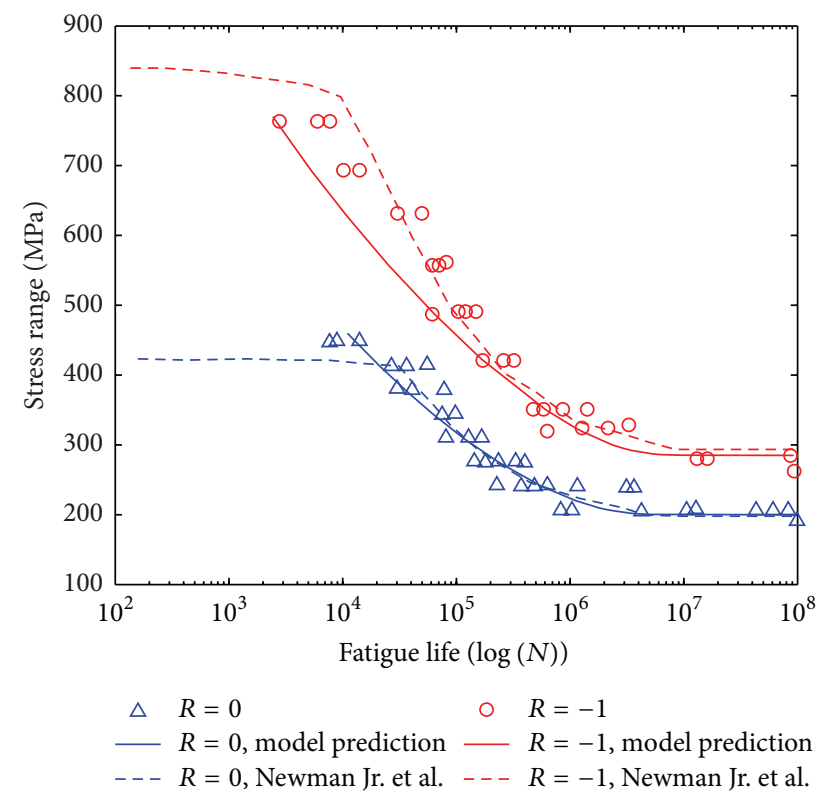

FIGURE 5: The calculated fatigue lives and test data for smooth Al2024-T3 specimens.

points are used in fitting the fatigue limit, such as the smooth Al7075-T6 specimens under $R=-1$. If the experimental data show larger discrepancies, the conservative data point is considered in determining the fatigue limit, and the weight should also be taken into account, such as the smooth Al7075T6 specimens under $R=0$. The little change in the value of fatigue limit will not have a significant effect on model predictions. Figure 6 shows the calculated fatigue lives of smooth Al2024-T3 specimens under $R=0$ using different

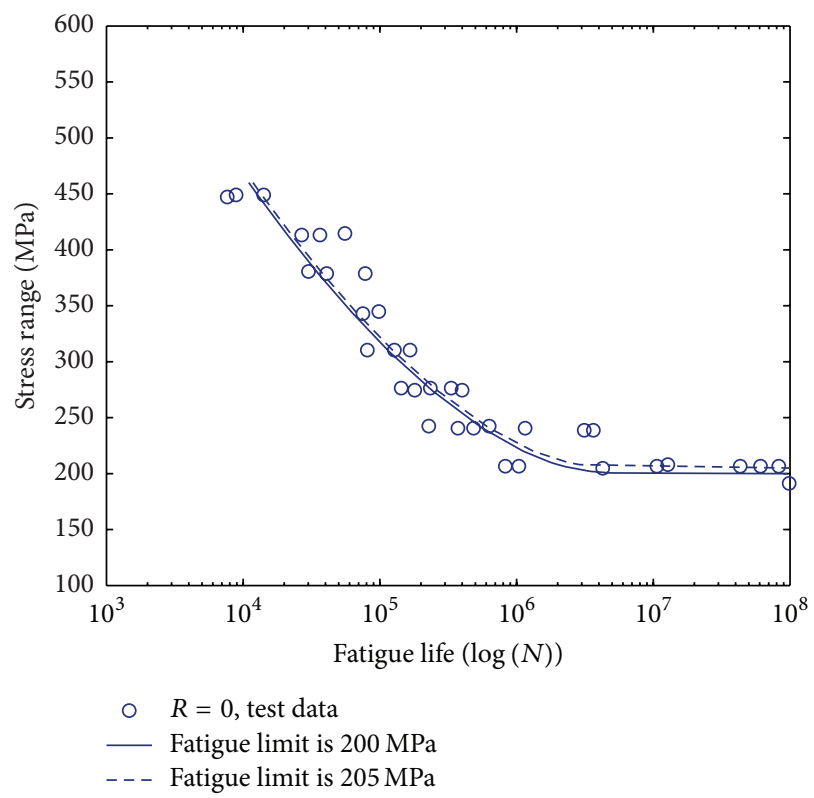

FIGURE 6: Life predictions using different values of fatigue limit.

values of fatigue limit. It can be seen from Figure 6 that the life prediction results are almost the same.

There are some discrepancies existing between the calculated fatigue lives and experimental data, especially under high stress range. One possible reason is that the coalescence of multiple cracks is predominant in the early crack propagation stage $[44,45]$, and the crack size may increase abruptly. The abrupt change in the crack size is not considered in the proposed method. Besides, the crack depth is assumed to be equal to the crack length which may also cause discrepancies. 
In this study, a simple and efficient fatigue life prediction algorithm based on the LEFM is proposed. The crack propagation model is based on the modified NASGRO equation. The concept of intrinsic effective threshold SIF range $\left(\Delta K_{\text {eff }}\right)_{\text {th }}$ is introduced in the modified NASGRO equation. The value of $\left(\Delta K_{\text {eff }}\right)_{\text {th }}$ is determined by back-extrapolation. The fatigue limit and intrinsic effective threshold SIF range $\left(\Delta K_{\text {eff }}\right)_{\text {th }}$ are employed to estimate the initial defect size. The following conclusions can be drawn:

(1) Only large crack propagation data are required in the proposed life prediction algorithm, and the algorithm can avoid the complicated analysis of small-crack propagation. A number of test data verified the effectiveness of the proposed life prediction algorithm.

(2) $\left(\Delta K_{\text {eff }}\right)_{\text {th }}$ is considered as the material property which is independent of stress ratios, and it is obtained from large crack growth data by back-extrapolation.

(3) The proposed algorithm is validated by two aluminum alloys (Al2024-T3 and Al7075-T6) under constant amplitude loading, and it can calculate fatigue lives of any structure materials if the corresponding accurate $\Delta K$ solutions are available.

\section{Competing Interests}

The authors declare that there is no conflict of interests regarding the publication of this paper.

\section{Acknowledgments}

The research is financially supported by the National Natural Science Foundation of China (no. 51405009) and the Fundamental Research Funds for the Central Universities.

\section{References}

[1] O. H. Basquin, "The exponential law of endurance tests," Proceedings of the American Society for Testing and Materials, vol. 10, no. 2, pp. 625-630, 1910.

[2] L. Coffin and J. Tavernelli, "The cyclic straining and fatigue of metals," Transactions of the Metallurgical Society of AIME, vol. 215, pp. 794-807, 1959.

[3] S. S. Manson, "Fatigue: a complex subject-some simple approximations," Experimental Mechanics, vol. 5, no. 7, pp. 193226, 1965.

[4] N. T. Ninh and M. A. Wahab, "The effect of residual stresses and weld geometry on the improvement of fatigue life," Journal of Materials Processing Technology, vol. 48, no. 1-4, pp. 581-588, 1995.

[5] M. Shirani and G. Härkegård, "Fatigue life distribution and size effect in ductile cast iron for wind turbine components," Engineering Failure Analysis, vol. 18, no. 1, pp. 12-24, 2011.

[6] M. A. S. Torres and H. J. C. Voorwald, "An evaluation of shot peening, residual stress and stress relaxation on the fatigue life of AISI 4340 steel," International Journal of Fatigue, vol. 24, no. 8, pp. 877-886, 2002.

[7] K. Walker, "The effect of stress ratio during crack propagation and fatigue for 2024-T3 and 7075-T6 aluminum," in Effects of
Environment and Complex Load History on Fatigue Life, ASTM International, West Conshohocken, Pa, USA, 1970.

[8] A. H. Noroozi, G. Glinka, and S. Lambert, "A study of the stress ratio effects on fatigue crack growth using the unified twoparameter fatigue crack growth driving force," International Journal of Fatigue, vol. 29, no. 9-11, pp. 1616-1633, 2007.

[9] S. Jiang, W. Zhang, X. Li, and F. Sun, "An analytical model for fatigue crack propagation prediction with overload effect," Mathematical Problems in Engineering, vol. 2014, Article ID 713678, 9 pages, 2014.

[10] S. I. Rokhlin, J.-Y. Kim, H. Nagy, and B. Zoofan, "Effect of pitting corrosion on fatigue crack initiation and fatigue life," Engineering Fracture Mechanics, vol. 62, no. 4-5, pp. 425-444, 1999.

[11] D. R. Carter and W. C. Hayes, "Fatigue life of compact bone-I effects of stress amplitude, temperature and density," Journal of Biomechanics, vol. 9, no. 1, pp. 27-34, 1976.

[12] A. T. Stewart, "The influence of environment and stress ratio on fatigue crack growth at near threshold stress intensities in lowalloy steels," Engineering Fracture Mechanics, vol. 13, no. 3, pp. 463-478, 1980.

[13] P. Paris and F. Erdogan, "A critical analysis of crack propagation laws," Journal of Basic Engineering, vol. 85, no. 4, pp. 528-533, 1963.

[14] E. K. Priddle, "High cycle fatigue crack propagation under random and constant amplitude loadings," International Journal of Pressure Vessels and Piping, vol. 4, no. 2, pp. 89-117, 1976.

[15] R. G. Forman, V. E. Kearney, and R. M. Engle, "Numerical analysis of crack propagation in cyclic-loaded structures," Journal of Basic Engineering, vol. 89, no. 3, pp. 459-463, 1967.

[16] W. Elber, "The significance of fatigue crack closure," ASTM STP, vol. 486 , pp. 230-243, 1971.

[17] S. Suresh, G. F. Zamiski, and D. R. O. Ritchie, "Oxide-induced crack closure: an explanation for near-threshold corrosion fatigue crack growth behavior," Metallurgical Transactions A, vol. 12, no. 8, pp. 1435-1443, 1981.

[18] G. T. Gray, J. C. Williams, and A. W. Thompson, "Roughnessinduced crack closure: an explanation for microstructurally sensitive fatigue crack growth," Metallurgical Transactions A, vol. 14, no. 2, pp. 421-433, 1983.

[19] P. C. Paris, H. Tada, and J. K. Donald, "Service load fatigue damage-a historical perspective," International Journal of Fatigue, vol. 21, no. 1, pp. S35-S46, 1999.

[20] J. C. Newman Jr., "A crack-closure model for predicting fatigue crack growth under aircraft spectrum loading," ASTM STP, vol. 748, pp. 53-84, 1981.

[21] J. C. Newman Jr., "A crack opening stress equation for fatigue crack growth," International Journal of Fracture, vol. 24, no. 4, pp. R131-R135, 1984.

[22] D. S. Dugdale, "Yielding of steel sheets containing slits," Journal of the Mechanics and Physics of Solids, vol. 8, no. 2, pp. 100-104, 1960.

[23] N. Consortium, "Fatigue crack growth computer program NASGRO ${ }^{\circledR}$ version 3.0. user manual," NASA Technical Report JSC-22267B, 2001.

[24] R. Forman, V. Shivakumar, J. Cardinal, L. Williams, and P. McKeighan, "Fatigue crack growth database for damage tolerance analysis," Final Report No. DOT/FAA/AR-05/15, US Department of Transportation Federal Aviation Administration (FAA), Office of Aviation Research, Washington, DC, USA, 2005. 
[25] J. C. Newman Jr., "FASTRAN-2: a fatigue crack growth structural analysis program," NASA STI/Recon Technical Report N 92:30964, 1992.

[26] J. C. Newman Jr., E. P. Phillips, and M. H. Swain, "Fatiguelife prediction methodology using small-crack theory," International Journal of Fatigue, vol. 21, no. 2, pp. 109-119, 1999.

[27] J. C. Newman Jr., "Fatigue-life prediction methodology using a crack-closure model," Journal of Engineering Materials and Technology, vol. 117, no. 4, pp. 433-439, 1995.

[28] J. C. Newman Jr., E. L. Anagnostou, and D. Rusk, "Fatigue and crack-growth analyses on 7075-T651 aluminum alloy coupons under constant- and variable-amplitude loading," International Journal of Fatigue, vol. 62, pp. 133-143, 2014.

[29] K. J. Miller and E. De Los Rios, The Behaviour of Short Fatigue Cracks, Mechanical Engineering Publications, Suffolk, UK, 1986.

[30] "Applicability of fracture mechanics to very small cracks or the cracks in the early stage," in Proceedings of the 2nd International Conference on Mechanical Behavior of Materials ASM, $\mathrm{H}$. Kitagawa and S. Takahashi, Eds., pp. 627-631, Metals Park, Ohio, USA, 1976.

[31] J. Schijve, The Practical and Theoretical Significance of Small Cracks: An Evaluation, Delft University of Technology, 1984.

[32] Y. Liu and S. Mahadevan, "Probabilistic fatigue life prediction using an equivalent initial flaw size distribution," International Journal of Fatigue, vol. 31, no. 3, pp. 476-487, 2009.

[33] J. Schijve, Fatigue of Structures and Materials, Springer, Berlin, Germany, 2001.

[34] J. Newman Jr., J. Schneider, A. Daniel, and D. McKnight, "Compression pre-cracking to generate near threshold fatiguecrack-growth rates in two aluminum alloys," International Journal of Fatigue, vol. 27, no. 10-12, pp. 1432-1440, 2005.

[35] J. C. Newman Jr. and B. S. Annigeri, "Fatigue-life prediction method based on small-crack theory in an engine material," Journal of Engineering for Gas Turbines and Power, vol. 134, no. 3, Article ID 032501, 2012.

[36] M. H. El Haddad, T. H. Topper, and K. N. Smith, "Prediction of non propagating cracks," Engineering Fracture Mechanics, vol. 11 , no. 3, pp. 573-584, 1979.

[37] J. Newman Jr. and I. Raju, "Stress-intensity factor equations for cracks in three-dimensional finite bodies subjected to tension and bending loads," Computational Methods in the Mechanics of Fracture, vol. 2, pp. 311-334, 1986.

[38] J. Newman Jr. and I. Raju, "Stress-intensity factor equations for cracks in three-dimensional finite bodies," American Society for Testing and Materials Selected Technical Paper, vol. 791, pp. 238265, 1983.

[39] X. Huang, M. Torgeir, and W. Cui, "An engineering model of fatigue crack growth under variable amplitude loading," International Journal of Fatigue, vol. 30, no. 1, pp. 2-10, 2008.

[40] C. A. Rodopoulos, S. A. Curtis, E. R. de Los Rios, and J. SolisRomero, "Optimisation of the fatigue resistance of 2024-T351 aluminium alloys by controlled shot peening-methodology, results and analysis," International Journal of Fatigue, vol. 26, no. 8, pp. 849-856, 2004.

[41] T. Zhao and Y. Jiang, "Fatigue of 7075-T651 aluminum alloy," International Journal of Fatigue, vol. 30, no. 5, pp. 834-849, 2008.

[42] C. Bathias, "There is no infinite fatigue life in metallic materials," Fatigue and Fracture of Engineering Materials and Structures, vol. 22, no. 7, pp. 559-565, 1999.
[43] B. Pyttel, D. Schwerdt, and C. Berger, "Very high cycle fatigueis there a fatigue limit?" International Journal of Fatigue, vol. 33, no. 1, pp. 49-58, 2011.

[44] P. R. Frise and R. Bell, "Modelling fatigue crack growth and coalescence in notches," International Journal of Pressure Vessels and Piping, vol. 51, no. 1, pp. 107-126, 1992.

[45] R. N. Parkins, "The application of stress corrosion crack growth kinetics to predicting lifetimes of structures," Corrosion Science, vol. 29, no. 8, pp. 1019-1038, 1989. 


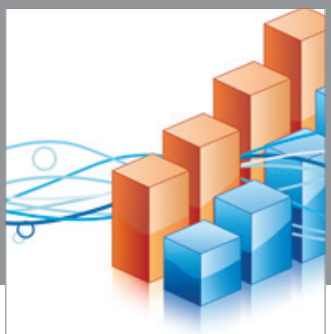

Advances in

Operations Research

vatem alat4

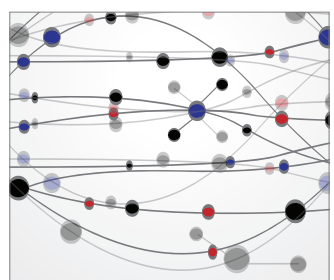

\section{The Scientific} World Journal
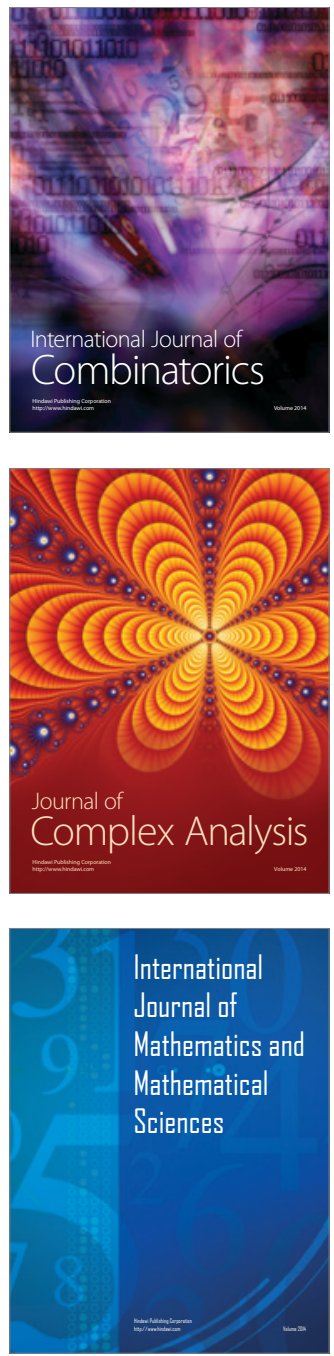
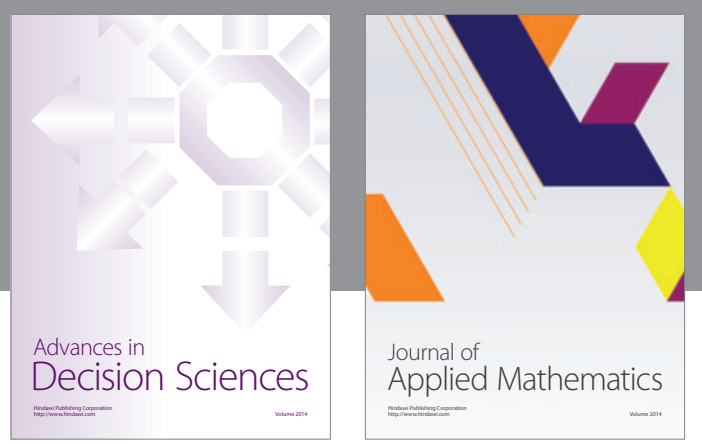

Algebra

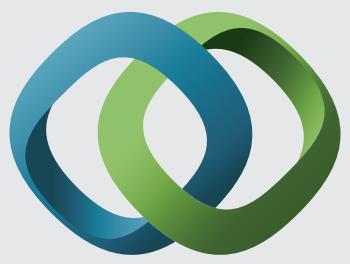

\section{Hindawi}

Submit your manuscripts at

http://www.hindawi.com
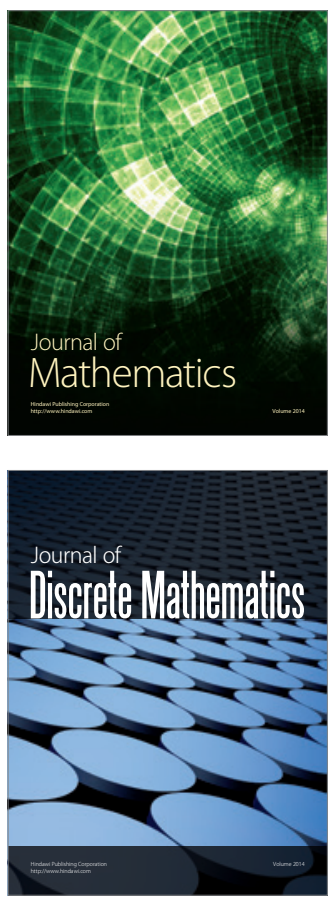

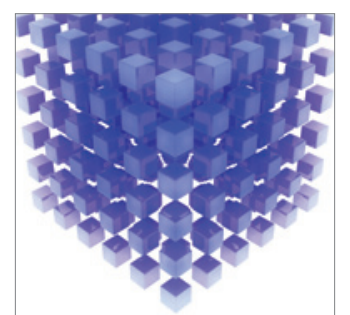

Mathematical Problems in Engineering
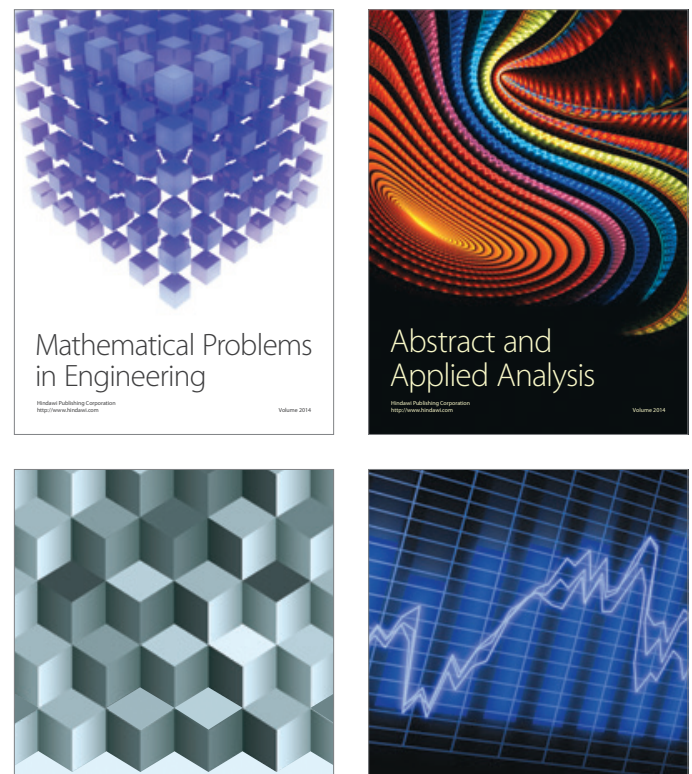

Journal of

Function Spaces

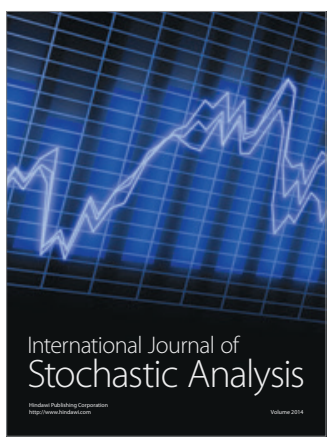

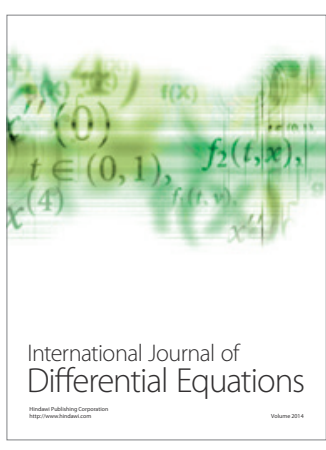
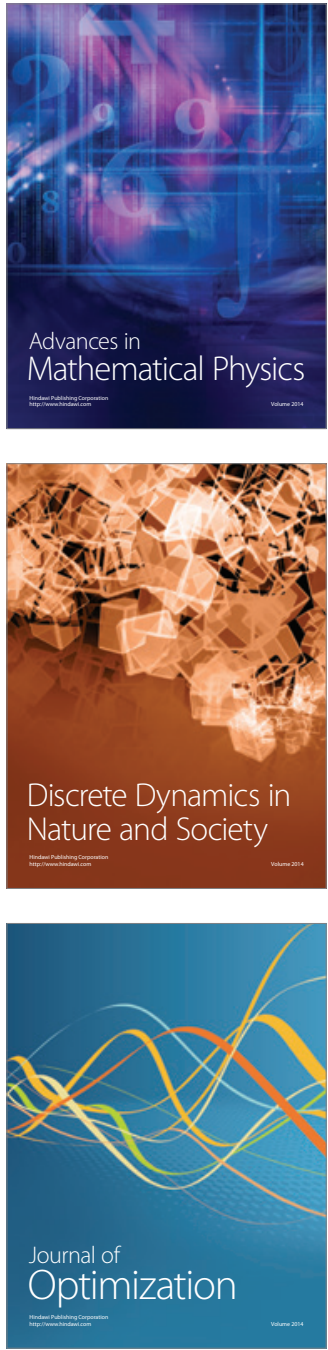